\title{
DETERMINAÇÃO ELETROANALÍTICA DE CORANTE REATIVO PRESENTE COMO CONTAMINANTE EM PROTEÍNAS PURIFICADAS POR CROMATOGRAFIA DE AFINIDADE.
}

\author{
Marly E. Osugi, Claudia C. I. Guaratini, Nelson R. Stradiotto e Maria Valnice Boldrin Zanoni*
}

Departamento de Química Analítica, Instituto de Química, Universidade Estadual Paulista, CP 355, 14801-970 Araraquara - SP

Recebido em 8/7/03; aceito em 31/10/03

\begin{abstract}
ELECTROANALYTICAL DETERMINATION OF A REACTIVE DYE CURRENTLY USED IN AFFINITY CHROMATOGRAPHY FOR PROTEIN PURIFICATON. Procion Green HE-4BD is a reactive dye currently used in affinity purification, and commonly present as a contaminant in the final biological preparation. An assay method is described to determine trace amounts of the dye in the presence of human serum albumin(HSA) and leakage from agarose as affinity sorbent by cathodic stripping voltammetry. The proposed method is based on the reductive peak at $-0.55 \mathrm{~V}$ in $\mathrm{B}-\mathrm{R}$ buffer $\mathrm{pH} 3(\mathrm{E}=0 \mathrm{~V}$ and $\mathrm{t}=240 \mathrm{~s})$, obtained when samples of HSA $2 \%(\mathrm{~m} / \mathrm{v})$ containing dye concentrations in sodium hydroxide $\mathrm{pH} 12$ are submitted to a heating time of $330 \mathrm{~min}$ at $80{ }^{\circ} \mathrm{C}$. Linear calibration curves can be obtained for RG19 dye concentrations from $5 \times 10^{-9} \mathrm{~mol} \mathrm{~L}^{-1}$ to $8 \times 10^{-8}$ mol L-1. The detection limit $(3 \sigma)$ is $1 \times 10^{-9} \mathrm{~mol} \mathrm{~L}^{-1}$.
\end{abstract}

Keywords: triazine dyes; cathodic stripping voltammetry; purified biomaterials.

\section{INTRODUÇÃO}

Corantes reativos são amplamente utilizados como alternativa de menor custo na purificação de proteínas por meio da técnica de cromatografia de afinidade. $\mathrm{O}$ grande interesse e alta demanda por proteínas e enzimas com alto grau de pureza torna-se cada vez maior em biotecnologia, bioquímica e medicina e tem contribuído de forma significativa para o crescimento desta área nos últimos anos ${ }^{1}$.

A purificação de proteína pelo método de afinidade baseia-se na utilização de colunas contendo suportes derivatizados com corantes reativos, capazes de interagir com proteínas de interesse com alta especificidade $^{2}$. Dentre os diversos tipos de corantes reativos usados para esta finalidade, destacam-se os que contém grupos triazinas como centro reativo ${ }^{2-6}$. Esses corantes são capazes de se ligarem tão fortemente à proteína que esta pode ser separada de misturas extremamente complexas em uma simples etapa de purificação. Esta metodologia tem ganho notoriedade por fornecer um método econômico e confiável para separação de proteínas, utilizando-se como simples etapa suportes modificados por estes corantes. Entretanto, uma das desvantagens freqüentemente mencionadas na utilização destes corantes imobilizados para a purificação de proteínas é quanto ao risco de contaminação da preparação biológica por traços do corante ${ }^{2}$.

O corante Procion Green HE-4BD (RG19), Figura 1, pertence à família de corantes reativos que podem ser acoplados a uma enorme variedade de suportes cromatográficos, tais como agarose, celulose, poliacrilamida, sephadex, silica e vidro ${ }^{6-8}$. Este corante imobilizado em colunas cromatográficas tem permitido a purificação de uma gran-

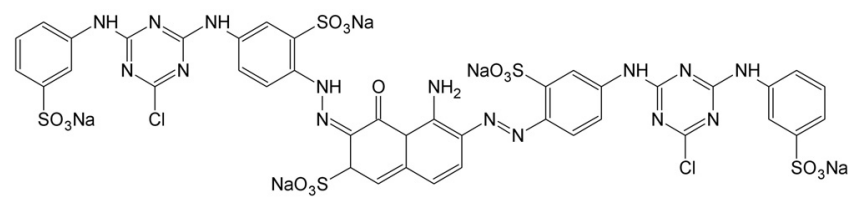

Figura 1. Corante Reativo Procion Green HE-4BD (RG19)

\footnotetext{
*e-mail: boldrinv@iq.unesp.br
}

de quantidade de proteínas. Para se obter uma extração efetiva, além do requerimento de um alto grau de pureza da proteína obtida como produto final, os suportes usados na fase estacionária e preparados previamente com a etapa de imobilização do corante também devem apresentar um nível de concentração desprezível em corante livre. Deste modo, métodos analíticos cada vez mais sensíveis são requeridos para estas operações.

Os métodos analíticos freqüentemente citados na literatura para esta finalidade são baseados nos métodos espectrofotométricos clássicos, cromatográficos ou na utilização de testes imunoenzimáticos ${ }^{4,6}$. Os métodos espectrofotométricos clássicos não são suficientemente sensíveis para aplicação em nível de concentração compatível com o requerido e, paralelamente, os métodos cromatográficos e imunoenzimáticos são bastante complexos e dispendiosos, envolvendo longas etapas de extração e preparação da amostra.

A utilização dos métodos voltamétricos de redissolução catódica para análise de traços de corantes reativos em meio aquoso foi previamente investigada $^{9-12}$. A adsorção espontânea do corante RG19 sobre eletrodo de mercúrio tem permitido sua determinação em níveis de concentração menores que $10^{-9} \mathrm{~mol} \mathrm{~L}^{-1}$ em meio aquoso ${ }^{10}$, utilizando-se uma simples etapa de pré-concentração sob potencial e tempo controlado. O presente trabalho investiga um novo método analítico para determinação de traços do corante RG19 como impureza, oriunda da lixiviação de suportes cromatográficos e purificação de proteínas por voltametria de redissolução catódica.

\section{PARTE EXPERIMENTAL}

Todas as medidas voltamétricas foram realizadas em Potenciostato/Galvanostato EG\&G PARC modelo 284, acoplado a um sistema contendo um eletrodo de mercúrio EG\&G PARC modelo 303A. Um eletrodo de fio de platina e um eletrodo de $\mathrm{Ag} / \mathrm{AgCl}(3 \mathrm{M})$ foram utilizados como eletrodo auxiliar e referência, respectivamente. Todas as medidas de $\mathrm{pH}$ foram realizadas em pHmetro Metrohm E500 com eletrodo de vidro combinado Metrohm EA 121, previamente calibrado.

Soluções estoque do corante RG19 (Aldrich) foram preparadas pela dissolução em água deionizada em sistema Milli Q (Millipore). 
Soluções tampão Britton-Robinson (B-R) foram preparadas pela mistura de ácido acético, ácido bórico, ácido o-fosfórico $\left(0,4 \mathrm{~mol} \mathrm{~L}{ }^{-1}\right)$ e solução de hidróxido de sódio $0,2 \mathrm{~mol} \mathrm{~L}^{-1}$. Todas as soluções foram preparadas com reagente suprapuro (Merck). Uma alíquota da solução padrão a ser investigada foi transferida para uma célula voltamétrica contendo $10 \mathrm{~mL}$ da solução tampão com pH apropriado. Os voltamogramas de redissolução foram obtidos usando uma etapa de pré-acúmulo durante agitação sob potencial e tempo controlado e pré-estabelecido experimentalmente. Após $15 \mathrm{~s}$ de repouso da solução, os voltamogramas foram registrados no módulo de varredura de pulso diferencial utilizando-se uma amplitude de pulso de $50 \mathrm{mV}$.

Para os testes de lixiviação, 2,0 ml de agarose foi incubado com $2 \mathrm{~mL}$ de tampão B-R em valores de pH 2,0 e 12,0 durante 24 h à temperatura ambiente. Após incubação, cada sobrenadante foi coletado por centrifugação e as alíquotas recolhidas e adicionadas diretamente à celula voltamétrica contendo tampão B-R pH 3,0.

Reações de hidrólise foram realizadas pelo aquecimento de soluções do corante ou da mistura corante/soro albumina humana em hidróxido de sódio pH 12,0, em concentração apropriada e aquecidas em banho termostático (Nova Técnica) sob temperatura controlada de $80{ }^{\circ} \mathrm{C}$. Após aquecimento, as soluções foram resfriadas em banho de gelo, e as análises realizadas após remoção de alíquota e diluição em 10,0 mL de tampão B-R pH 3,0 à temperatura ambiente.

\section{RESULTADOS E DISCUSSÃO}

A Figura 2 mostra voltamograma de redissolução catódica com varredura de pulso diferencial para redução de $5,0 \times 10^{-7} \mathrm{~mol} \mathrm{~L}^{-1}$ do corante RG 19 em tampão B-R pH 3,0, após pré-concentração sob potencial de acúmulo $\left(\mathrm{E}_{\mathrm{ac}}\right)$ de $0 \mathrm{~V}$ e tempo de acúmulo $\left(\mathrm{t}_{\mathrm{ac}}\right)$ de $30 \mathrm{~s} . \mathrm{O}$ corante na forma adsorvida é reduzido em quatro etapas. Os dois primeiros picos de redução, verificados em potenciais menos catódicos de $\mathrm{E}_{\mathrm{p}}-0,08 \mathrm{~V}$ (I) e $\mathrm{E}_{\mathrm{p}}-0,17 \mathrm{~V}$ (II), são atribuídos às reduções sucessivas dos dois grupos azos (cromóforo) influenciados pelos grupos amino e hidroxila adjacentes nos anéis aromáticos ${ }^{9,10}$. Os picos de redução exibidos em potenciais mais negativos, $\mathrm{E}_{\mathrm{p}} \mathrm{de}$ $-0,81 \mathrm{~V}$ (III) e $\mathrm{E}_{\mathrm{p}}$ de $-0,96 \mathrm{~V}$ (IV), são atribuídos às reduções sucessivas da ligação $\mathrm{R}-\mathrm{Cl}$ dos dois grupos clorotriazinas, localizadas nas extremidades da molécula do corante $\mathrm{e}^{9,10}$.

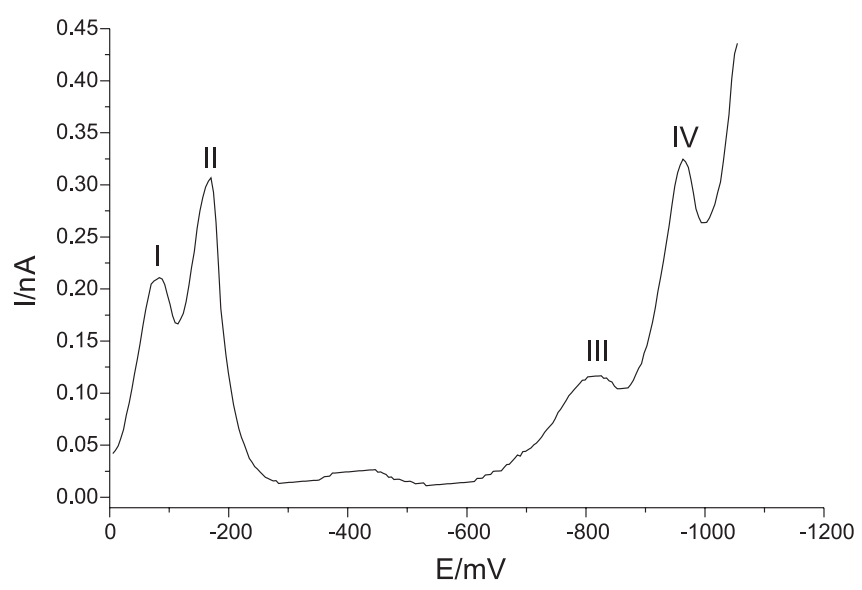

Figura 2. Voltamograma de redissolução catódica com pulso diferencial para redução de $5 \times 10^{-7} \mathrm{~mol} \mathrm{~L}^{-1}$ do corante $R G 19$ em tampão $B-R$ pH 3,0. $E_{a c}=0$ V e $t_{a c}=30 \mathrm{~s}$

A aplicação da técnica voltamétrica para determinação de traços de corante RG19 proveniente do mecanismo de liberação de suporte cromatográfico foi investigada, utilizando-se amostras comerciais de agarose contendo o corante RG19 imobilizado como modelo de fase estacionária, utilizando-se procedimento descrito na Parte Experimental.

A Figura 3 (Curva b), mostra um voltamograma de redissolução catódica característico obtido para o sobrenadante recolhido em meio alcalino, neutralizado e diluído em tampão B-R pH 3,0, submetido a potencial de $0 \mathrm{~V}$ durante $30 \mathrm{~s}$. A redução dos dois grupos azo ocorre em potenciais semelhantes àqueles do corante original submetido as mesmas condições experimentais. No entanto, a redução do grupo clorotriazina mostra apenas um pico ao redor de $-1,0 \mathrm{~V}$, indicando que, provavelmente, um dos grupos clorotriazina foi inativado irreversivelmente em meio alcalino, devido a hidrólise do corante original $^{11}$. No entanto, as curvas c e d da Figura 3 mostram que, após adições sucessivas de $1,0 \times 10^{-6} \mathrm{~mol} \mathrm{~L}^{-1}$ do corante RG19 em meio alcalino de $\mathrm{pH}$ 12,0 e neutralização de forma semelhante ao procedimento experimental adotado para o sobrenadante, há subsequiente aumento da corrente dos três picos de redução. A quantificação do conteúdo de corante RG19 no sobrenadante foi monitorada pelo método da adição de padrão de amostras de $1 \times 10^{-6} \mathrm{~mol} \mathrm{~L}^{-1}$ do corante RG19 em meio alcalino de pH 12,0 e neutralizado com pH 3,0. Valores médios de $73 \pm 2,03 \mathrm{nA}$ foram obtidos para a corrente correspondente ao segundo pico, indicando que $1,9 \times 10^{-6} \mathrm{~mol} \mathrm{~L}^{-1}$ do corante RG19 foi lixiviado nas alíquotas recolhidas em sobrenadante das amostras de agarose com corante imobilizado, submetidas à incubação em meio alcalino. O mesmo procedimento foi repetido para amostras do sobrenadante proveniente de agarose/ corante em meio ácido ( $\mathrm{pH}$ 2,0). Entretanto, os voltamogramas não apresentaram nenhum pico mensurável por voltametria de redissolução catódica, mostrando que a lixiviação do corante da fase estacionária nestas condições é menor que o limite de detecção ${ }^{11}$ apresentado pela técnica $\left(5,0 \times 10^{-10} \mathrm{~mol} \mathrm{~L}^{-1}\right)$.

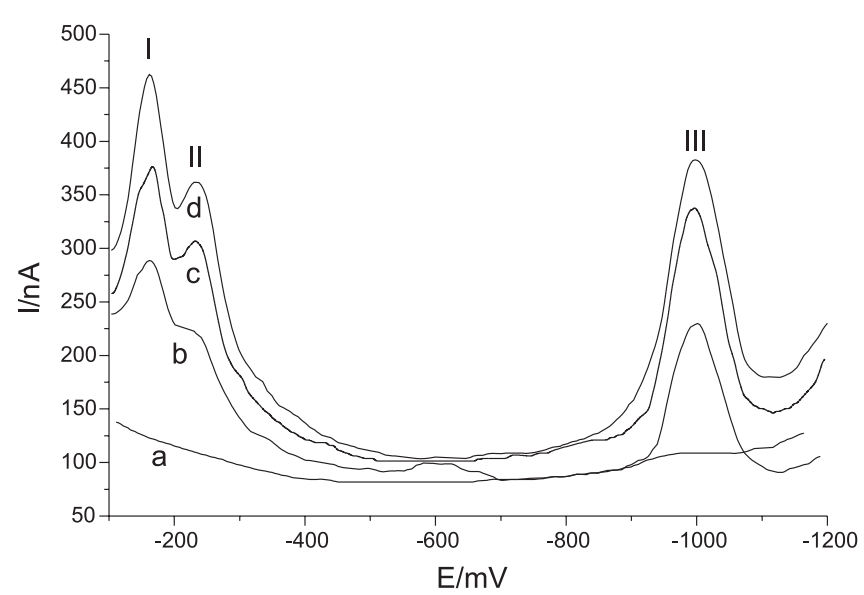

Figura 3. Voltamograma de redissolução catódica com pulso diferencial do sobrenadante recolhido da amostra do corante RG19 imobilizado em agarose após incubação em tampão $B-R$ pH 12, neutralização e adição direta em tampão B-R pH 3,0 (Curva b). Após adição de solução padrão do corante RG19: (Curva c) $1 \times 10^{-6} \mathrm{~mol} \mathrm{~L}^{-1}$; (Curva d) $2 \times 10^{-6} \mathrm{~mol} \mathrm{~L}^{-1}$ e (Curva a) eletrólito de suporte. Eacc $=0$ V e tacc $=30 \mathrm{~s}$

A seguir, investigou-se a possibilidade de se usar o método voltamétrico de redissolução catódica também para a quantificação do corante em amostras de soro de albumina humana (SAH) contaminadas pelo corante RG19. A adição de SAH entre concentrações de 0,01 a $2,0 \%(\mathrm{~m} / \mathrm{v})$ diretamente à célula eletroquímica contendo $5,0 \times 10^{-7} \mathrm{~mol} \mathrm{~L}^{-1}$ do corante RG19 levou à sucessiva diminuição dos picos de redução do grupo clorotriazina em concentrações menores que $0,05 \%(\mathrm{~m} / \mathrm{v})$, sugerindo que a reação entre corante/proteína ina- 
tiva este grupo na molécula. Em concentrações superiores de SAH, observa-se a supressão parcial de todos os outros grupos redutíveis, impedindo a análise direta do corante RG19 em amostras da proteína. Estes resultados sugerem que o corante RG19 interage fortemente com a proteína SAH e inativa eletroquimicamente o grupo reativo, sendo que altas concentrações da proteína devem competir pela mesma área superficial do eletrodo, uma vez que SAH também é adsorvida espontaneamente em eletrodo de mercúrio ${ }^{13,14}$.

Considerando que a forma hidrolisada do corante RG19 gerada sob condições de $\mathrm{pH}$ alcalino e alta temperatura pode também ser determinada por voltametria de redissolução catódica ${ }^{11}$ e que, nestas condições experimentais, a desnaturação da proteína poderia estar ocorrendo e, conseqüentemente, minimizando sua adsorção no eletrodo, investigou-se, a seguir, a possibilidade de se usar a hidrólise da mistura corante/proteína para análise do corante liberado na proteína purificada.

Amostras de $1,2 \times 10^{-4} \mathrm{~mol} \mathrm{~L}^{-1}$ do corante em hidróxido de sódio $\mathrm{pH} 12,0$, aquecidas por $240 \mathrm{~min}$ em temperatura de $80^{\circ} \mathrm{C}$, foram retiradas e adicionadas diretamente à célula contendo tampão $\mathrm{B}-\mathrm{R}$

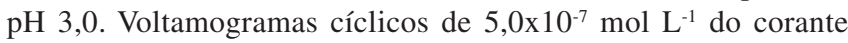
hidrolisado na célula obtidos sob pré-concentração de $240 \mathrm{~s}$ em potencial de $0 \mathrm{~V}$ mostram apenas dois picos de redução, correspondentes à redução dos dois grupos azo, seguidos de pequeno deslocamento de potencial para valores mais negativos, em $\mathrm{E}_{\mathrm{p}}-0,17 \mathrm{~V}$ e $\mathrm{E}_{\mathrm{p}}-0,26 \mathrm{~V}$, como mostra a Figura 4.

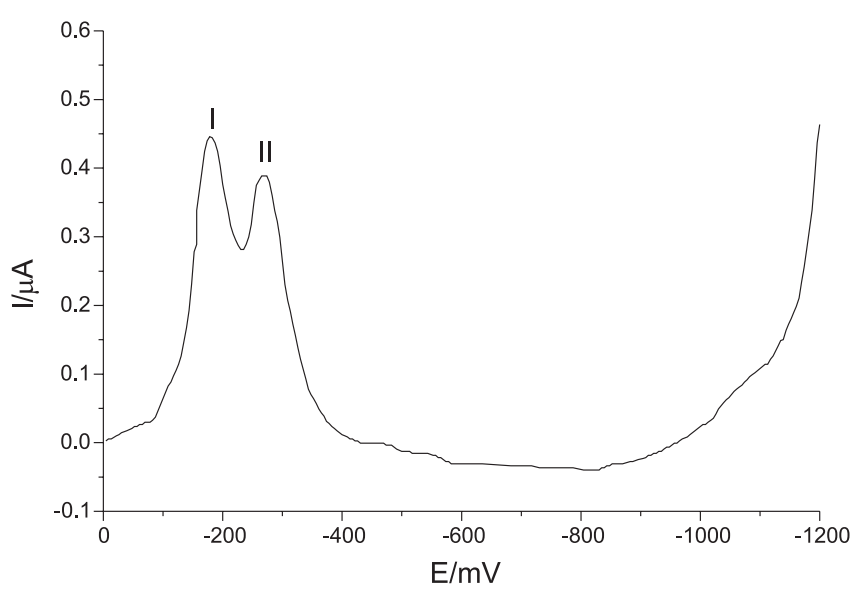

Figura 4. Voltamograma de redissolução catódica com pulso diferencial para redução de $5 \times 10^{-7} \mathrm{~mol} \mathrm{~L}^{-1}$ do corante $R G 19$ hidrolisado em meio alcalino pH 12, $T=80^{\circ} \mathrm{C}$ e aquecimento durante $330 \mathrm{~min}$, neutralizado e transferido para solução tampão $B-R \mathrm{pH} 3,0 . E_{\text {acc }}=0 \mathrm{~V}, t_{\text {acc }}=30 \mathrm{~s}$

Para efeito de comparação investigou-se o comportamento da proteína SAH em B-R pH 3,0. Os voltamogramas de redissolução catódica para $6,0 \times 10^{-3} \%(\mathrm{~m} / \mathrm{V})$ de SAH em tampão B-R pH 3,0 são caracterizados por um único pico em potencial de $-0,26 \mathrm{~V}$. A amostra após aquecimento por $240 \mathrm{~min}$ em hidróxido de sódio $\mathrm{pH}$ 12,0 sob temperatura de $80^{\circ} \mathrm{C}$, neutralização e diluição em tampão B-R $\mathrm{pH}$ 3,0 apresenta um pico intenso em $\mathrm{E}_{\mathrm{p}} \mathrm{de}-0,07 \mathrm{~V}$. Segundo a literatura $^{15,16}$, reações envolvendo desnaturação de soro de albumina humana ocorrem segundo a clivagem da ligação dissulfeto gerando resíduos do aminoácido cisteína, que são facilmente complexados com mercúrio e redutíveis em potenciais menos negativos que a $\mathrm{SAH}$ original. Assim, por comparação do sinal voltamétrico para redução da proteína e do corante, é possível concluir que sob condições de hidrólise seria possível detectar tanto a proteína quanto o corante hidrolisado.
A seguir, solução $2,0 \%(\mathrm{~m} / \mathrm{v})$ de SAH e $1 \times 10^{-4} \mathrm{~mol} \mathrm{~L}^{-1}$ do corante em hidróxido de sódio $\mathrm{pH} 12$ foram misturadas e submetidas a aquecimento durante $330 \mathrm{~min}$ a $\mathrm{T}=80^{\circ}$. Alíquotas da solução final após resfriamento foram adicionadas diretamente à solução tampão B-R pH 3,0. A Figura 5 apresenta voltamograma de redissolução catódica da redução de $3,6 \times 10^{-7} \mathrm{~mol} \mathrm{~L}^{-1}$ do corante hidrolisado na presença de $\mathrm{SAH}$, submetido a pré-concentração por $30 \mathrm{~s}$ sob potencial de $0 \mathrm{~V}$. Um pico de redução bem definido em potencial $-0,55 \mathrm{~V}$ e um pequeno pico de menor intensidade em potencial de $-0,26 \mathrm{~V}$ são observados, cujas correntes de pico se mantém estáveis durante $30 \mathrm{~min}$ em solução. Entretanto, a comparação entre os potenciais de pico com aqueles correspondentes à redução do corante e SAH hidrolisada sugere que o novo pico em $-0,55 \mathrm{~V}$ poderia ser atribuído a uma nova espécie gerada para o conjugado SAH/RG19 durante aquecimento. $\mathrm{O}$ pico de pequena intensidade em potencial menos negativo $(-0,26 \mathrm{~V})$ poderia ser atribuído à redução do corante hidrolisado livre (não ligado à proteína).

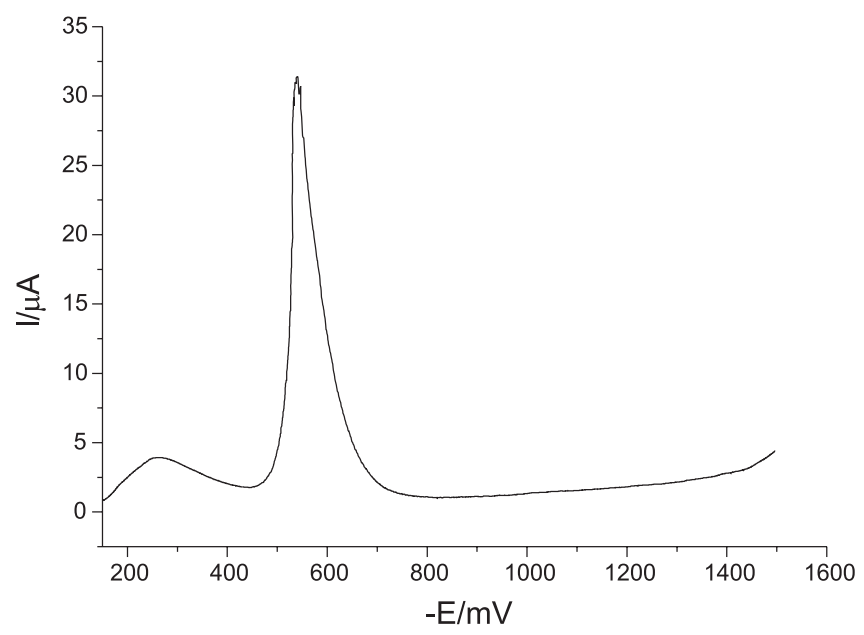

Figura 5.Voltamograma de redissolução catódica com pulso diferencial, obtido para redução da amostra recém hidrolisada de 3,6x10-7 $\mathrm{mol} \mathrm{L}^{-1}$ do composto RG19/SAH, em tampão B-R pH 3,0. $E_{a c}=0 \mathrm{Ve} t_{a c}=30 \mathrm{~s}$

Uma nova série de experimentos foi realizada tomando-se amostras recém hidrolisadas de misturas de SAH 2,0\% (m/v) contendo o corante RG19 nas concentrações de $2,0 \times 10^{-9} \mathrm{~mol} \mathrm{~L}^{-1}$ a $1,0 \times 10^{-8} \mathrm{~mol} \mathrm{~L}^{-1}$. A curva analítica correspondente ao corante em tampão B-R pH 3,0, sob $\mathrm{E}_{\mathrm{ac}}=0 \mathrm{~V}$ e $\mathrm{t}_{\mathrm{ac}}=240 \mathrm{~s}$, mostra uma relação linear no intervalo de $5,0 \times 10^{-9}$ mol L $\mathrm{L}^{-1}$ a $8,0 \times 10^{-8} \mathrm{~mol} \mathrm{~L}^{-1}$, segundo a equação: $\mathrm{I}_{\mathrm{p}}(\mu \mathrm{A})=$ $0,04119+0,3601 \mathrm{C}\left(\mathrm{C}=10^{-9} \mathrm{~mol} \mathrm{~L}^{-1}, \mathrm{n}=6, \mathrm{r}=0,9839\right)$. Alíquotas de $1,0 \mathrm{ml}$ de soluções de SAH 2,0\% (m/v) fortificadas com $1,2 \times 10^{-7} \mathrm{~mol} \mathrm{~L}^{-1}$ do corante RG19 em hidróxido de sódio $\mathrm{pH} 12,0$, aquecidas durante $330 \mathrm{~min}$ a $\mathrm{T}=80{ }^{\circ} \mathrm{C}$ e diluídas em $9,0 \mathrm{~mL}$ de tampão B-R pH 3,0, após resfriamento e repouso de 1 h em solução, foram submetidas à adição de padrão e o índice de recuperação obtido foi de $97,2 \pm 1,8 \%$. Estes resultados são indicativos de que é possível determinar o corante na forma do complexo SAH/RG19. O tratamento estatístico $(3 \sigma)$ mostrou que o método apresenta limite de detecção de $1,07 \times 10^{-9} \mathrm{~mol} \mathrm{~L}^{-1}$.

No entanto, voltamogramas registrados para as amostras após 30 min de repouso (Figura 6) em solução exibem um decréscimo da intensidade do pico em $-0,55 \mathrm{~V}$ (pico I), indicando a instabilidade do conjugado RG19/SAH. Concomitantemente, observa-se um aumento do pico em potencial de $-0,26 \mathrm{~V}$ (pico II) atribuído à redução do corante livre, que é liberado em função do tempo. Após $3 \mathrm{~h}$ em solução, ambos os picos são estabilizados e mantém-se inalterados em tempos superiores. 


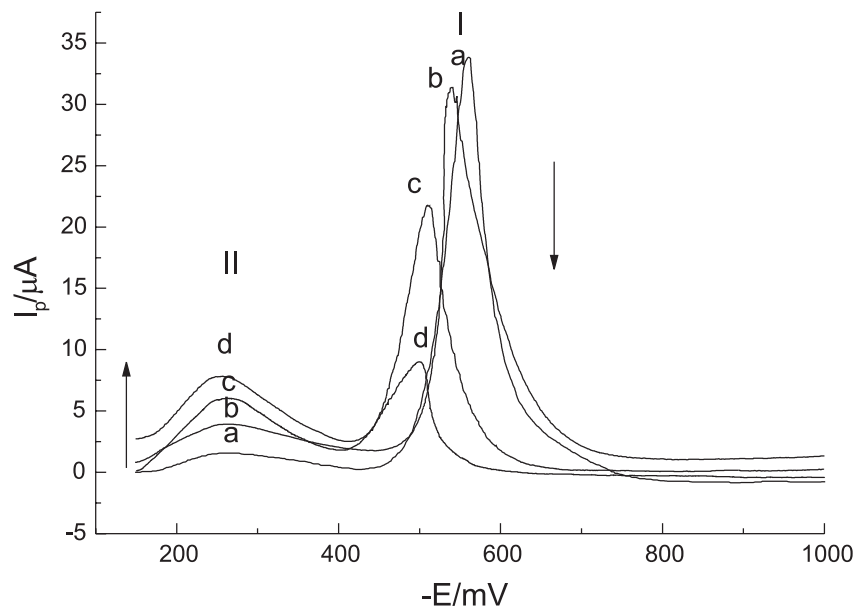

Figura 6. Efeito do tempo de repouso sobre os voltamogramas de redissolução catódica com pulso diferencial, obtidos para redução de 3,6x10-7 mol $L^{-1}$ do composto RG19/SAH, em tampão B-R pH 3,0. $E_{a c}=0 \mathrm{~V}$ e $t_{a c}=$ 30 s. Tempo: (a) 0; (b) 60; (c) 180 e (d) $240 \mathrm{~min}$

Embora, a metodologia descrita previamente seja adequada para análise do corante RG19 como contaminante em amostras de SAH, pela identificação do complexo RG19/SAH recém hidrolisado, investigou-se um método alternativo via determinação do corante liberado no complexo após longos tempos de repouso. Para tal, amostras de SAH 2,0\% (m/v) contendo concentração inicial do corante entre $5,0 \times 10^{-9}$ a $1,0 \times 10^{-7} \mathrm{~mol} \mathrm{~L}^{-1}$ foram submetidas à hidrólise prévia e o voltamograma registrado após repouso de $3 \mathrm{~h}$. A corrente de pico correspondente ao corante livre, redutível em potencial $\mathrm{E}_{\mathrm{p}}-0,25 \mathrm{~V}$ e proveniente da decomposição do conjugado RG19/SAH, foi monitorada utilizando-se voltamogramas submetidos à etapa de pré-concentração em $\mathrm{E}_{\mathrm{ac}}=0 \mathrm{~V}$ e tempo de acúmulo de $240 \mathrm{~s}$. Uma relação linear entre corrente de pico e concentração do corante é obtida no intervalo de $5,0 \times 10^{-9} \mathrm{~mol} \mathrm{~L}^{-1}$ a $2,0 \times 10^{-8} \mathrm{~mol} \mathrm{~L}^{-1}$ segundo a equação $\mathrm{I}_{\mathrm{p}}(\mu \mathrm{A})=-0,07813+0,11143 \mathrm{C}$, onde $\mathrm{C}=10^{-9} \mathrm{~mol} \mathrm{~L}^{-1} ; \mathrm{R}=0,997 \mathrm{e}$ $\mathrm{n}=7$. A reprodutibilidade do método foi avaliada testando-se cinco amostras de SAH 2,0\% (m/v) contendo $1,2 \times 10^{-7} \mathrm{~mol} \mathrm{~L}^{-1}$ do corante. O desvio padrão obtido foi de $3 \%$ entre as medidas e o limite de detecção foi de $3,9 \times 10^{-9} \mathrm{~mol} \mathrm{~L}^{-1}$. Estes resultados indicam que traços do corante reativo RG19 poderiam ser determinados em amostras de soro albumina humana por meio de voltamogramas de redissolução catódica correspondentes à redução do produto de hidrólise do conjugado corante/proteína ou do corante livre liberado após tempo de repouso superiores a $3 \mathrm{~h}$ em solução.

\section{CONCLUSÃO}

Os resultados obtidos indicam que a técnica voltamétrica de redissolução catódica pode ser uma alternativa simples e eficiente para identificação e quantificação do corante RG19 como contaminante em eluentes de suportes cromatográficos, tomando-se agarose como modelo. Em adição, o método permite ainda o monitoramento de traços do corante em amostras de preparações biológicas do tipo da soro albumina humana, por meio de simples etapa de hidrólise e pré-concentração sobre o eletrodo de mercúrio.

\section{AGRADECIMENTOS}

Os autores agradecem o auxílio financeiro da FAPESP, CNPq e CAPES.

\section{REFERÊNCIAS}

1. Haff, L. A.; Easterday, R. L.; Eckstein, F.; Sundaran, P. V.; Theory and Practice in Affinity Chromatography, Academic Press: New York, 1978.

2. Dean, P. D. G.; Johnson, W. S.; Middle, F. A.; Affinity Chromatography-A pratical Approach, IRL Press: Oxford, 1985.

3. Dean, P. D. G. ; Watson, D. H.; J. Chromatogr. 1979, 165, 301.

4. Burton, S. J.; Stead, C. V. ; Lowe, C. R.; J. Chromatogr. 1988, 455, 201.

5. Burton, S. J.; Stead, C. V.; Lowe, C. R.; J. Chromatogr. 1990, 508,109.

6. Santambien, P.; Girot, P.; Hulak, I.; Boschetti, E.; J. Chromatogr. 1992, $597,315$.

7. Watson, D. H.; Harvey, M .J.; Dean, P. D. G.; Biochem. J. 1978, 173, 591.

8. Travis, J.; Pannel, R.; Clin. Chim. Acta 1973, 49, 49.

9. Guaratini, C. C. I.; Fogg, A. G.; Zanoni, M. V. B.; Electroanalysis 2001, 13,1 .

10. Guaratini, C. C. I.; Fogg, A. G. ; Zanoni, M. V. B.; Dyes Pigm. 2001, 50, 211.

11. Guaratini, C. C. I.; Fogg, A. G.; Zanoni, M. V. B.; Microchem. J. 2002, 71,65 .

12. Zanoni, M. V. B.; Carneiro, P. A.; Furlan, M.; Guaratini, C. C. I.; Fogg, A. G.; Anal. Chim. Acta 1999, 385, 392.

13. Flores, M. R. S.; J. Electroanal. Chem. 1987, 235, 317.

14. Ferreira, V. S.; Zanoni, M. V. B.; Fogg, A. G.; Microchem. J. 1997, 57, 115 .

15. Hart, J. P.; Electroanalysis of Biologically Important Compounds, Ellis Horwood Ltd.: London, 1990.

16. Stankovich, M. T.; Bard, A. J.; J. Electroanal. Chem. 1978, 86, 189. 